\title{
An Alternative and Simple Method for the Preparation of Bare Silica Nanoparticles Using Sugarcane Waste Ash, an Abundant and Despised Residue in the Brazilian Industry
}

\author{
Suzimara Rovani, ${ }^{\odot *, a}$ Jonnatan J. Santos, ${ }^{b}$ Paola Corio $^{b}$ and Denise A. Fungaro ${ }^{a}$ \\ ${ }^{a}$ Instituto de Pesquisas Energéticas e Nucleares (IPEN-CNEN/SP), Av. Prof. Lineu Prestes, 2242, \\ Cidade Universitária, 05508-000 São Paulo-SP, Brazil \\ ${ }^{b}$ Instituto de Química, Universidade de São Paulo, Av. Prof. Lineu Prestes, 748, \\ Cidade Universitária, CP 26077, 05508-000 São Paulo-SP, Brazil
}

\begin{abstract}
Sugarcane waste ash, a Si-rich waste product, is generated in large quantities and creates a serious disposal problem in the Brazilian ethanol-sugar industry, affecting the environment and public health. Here, a simple method capable of generating bare silica nanoparticles utilizing this residue is demonstrated. Firstly, the crystalline silica present in sugarcane waste ash (SWA) was converted into amorphous by melting a mixture of sodium hydroxide and SWA at $550{ }^{\circ} \mathrm{C}$ for $1 \mathrm{~h}$. The silica nanoparticles $\left(\mathrm{SiO}_{2} \mathrm{NPs}\right)$ were formed by lowing $\mathrm{pH}$. This production process of $\mathrm{SiO}_{2} \mathrm{NPs}$ from SWA was optimized varying the ash:NaOH mass ratio, increasing the silica extraction up to $96 \%$. The sample's composition was characterized by total X-ray fluorescence spectroscopy, morphology and physical-chemical properties were investigated by scanning electron microscopy (SEM), transmission electron microscopy (TEM), X-ray diffraction, specific surface area measurements, Fourier-transform infrared spectroscopy (FTIR) and thermogravimetric analyses (TGA), followed by use as adsorbent for the removal of methylene blue dye. With this process of extraction, nanoparticles smaller than $100 \mathrm{~nm}$ were generated, with a surface area of $63 \mathrm{~m}^{2} \mathrm{~g}^{-1}$ and a maximum adsorption capacity of $37 \mathrm{mg} \mathrm{g}^{-1}$ for methylene blue. The results indicate a successful process for obtaining an adsorbent from an industrial waste product using a cost effective and rapid synthesis procedure rendering renewable product.
\end{abstract}

Keywords: silica nanoparticles, sugarcane waste ash, adsorbent

\section{Introduction}

Several questions are lifted when we think about sustainable agriculture, green energy and conscious consumption. Sugarcane is a product capable of playing a role in each one of these aspects and has been studied to a great extent, especially in Brazil, the $4^{\text {th }}$ largest agricultural producer and the largest sugarcane producer in the world. These points are crucial for the future, not only for the industry and the government, but also for the society in general.

Sugarcane is of immense importance to the Brazilian agricultural and economic industries. Considering only the current sugarcane plantations, it is expected that roughly 657 million tons of sugarcane were produced in 2018. ${ }^{1}$ Sugarcane is considered a renewable source for the generation of ethanol, a green fuel, and it can also be

*e-mail: suzimara.rovani@ipen.br; suziquimica@gmail.com used to generate sugar, an essential component of the food industry. After the production of ethanol and/or sugar, the sugarcane bagasse can then be burned for the generation of electricity, making sugarcane almost wholly utilized. The only leftover product is the ashes which correspond to around 12 million tons per year.

Sugarcane waste ash is a silica-rich by product generally forming more than $70 \%$ of the residue, ${ }^{2}$ and although this silica can be utilized as a raw material for the production of ceramics, glass, paints, polymers, rubber, cosmetics, catalyst, personal care products etc., ${ }^{3-6}$ the primary commercial source of silica is sand, typically in the form of quartz, where a melting process is utilized during the extraction. $^{7}$

Renewable adsorbent materials can be prepared from agro-industrial, biological or organic sources. At present, the search for a low-cost mode of preparation and high adsorption capacity continues ${ }^{8}$ Considering the adsorption properties, many different approaches are followed to 
obtain a high adsorption capacity, such as increasing the degree of porosity, decreasing the size of the particles (in turn increasing the surface area) or modifying the surface of the particles (introducing different molecules capable of interacting with contaminants). Several studies demonstrate how these properties can be controlled, aiming to remediate different types of contaminants with relative success. ${ }^{9-11}$

Sugarcane waste ash can be utilized to generate silica nanoparticles $\left(\mathrm{SiO}_{2} \mathrm{NPs}\right)$ in the presence of cetyltrimethylammonium bromide (CTAB), ${ }^{12}$ as previously demonstrated by our group; however, in this article the synthesis of bare silica nanoparticles without the presence of stabilizers is described. Nanoparticles without stabilizers have more applications due to the fact that they can be modified as needed, avoiding the problems generated by previously modified molecules, since removing molecules from the surface of nanoparticles in general, can cause destabilization or incompletion.

Thus, in this study, silica nanoparticles were produced utilizing sugarcane waste ash as feedstock. These nanoparticles had their composition, physical-chemical properties, and textural properties extensively studied by total X-ray fluorescence spectroscopy, scanning electron microscopy (SEM), transmission electron microscopy, $\mathrm{X}$-ray diffraction, attenuated total reflectance-infrared spectroscopy and thermogravimetric analyses. The role of the ash: $\mathrm{NaOH}$ ratio during the extraction of silica was investigated, and the nanoparticles that were obtained had their adsorptive capacity investigated for the removal of methylene blue dye from aqueous solutions, demonstrating the first possible application of this material.

\section{Experimental}

Materials

All aqueous solutions were prepared using deionized water (resistivity $>18.2 \mathrm{M} \Omega \mathrm{cm}$ ) obtained from a MilliQ deionizer (Elix Millipore, Germany). COSAN S.A., Brazil donated the sugarcane waste ash (SWA). Sodium hydroxide micro pearls (> 99\%), hydrochloric acid (35-37\%) and methylene blue (MB) dye were purchased from Synth, Brazil. An ammonia solution 25\% was purchased from Merck, Germany.

\section{Experimental procedure}

Extraction of sodium silicate from sugarcane waste ash was carried out by melting a mixture of sodium hydroxide and SWA at $550{ }^{\circ} \mathrm{C}$ for $1 \mathrm{~h}$, varying the proportion of ash: $\mathrm{NaOH}(1: 0.5 ; 1: 1.0 ; 1: 1.5$; and 1:2.0) by weight (w:w). ${ }^{13-15}$ After the mixture cooled down to room temperature, distilled water was added to the mixture and refluxed (at boiling point) for $4 \mathrm{~h}$, solubilizing all the sodium silicate in an aqueous medium. Then, a hydrochloric acid solution $\left(6.0 \mathrm{~mol} \mathrm{~L}^{-1}\right)$ was added drop by drop, until the $\mathrm{pH}$ decreased to 2.0. Concentrated $\mathrm{NH}_{4} \mathrm{OH}$ was then added until $\mathrm{pH}$ increased to $8.5 .^{13,14}$ The resulting gel was aged at room temperature for $12 \mathrm{~h}$. This aged nanosilica gel was washed with distilled water, filtered and oven dried at $120{ }^{\circ} \mathrm{C}$ overnight. The dried samples were washed for a second time with distilled water, aiming at the complete removal of sodium chloride and others salts, filtered and oven dried at $120^{\circ} \mathrm{C}$ overnight. The experimental procedure is resumed on Figure S1 (Supplementary Information (SI) section) and equations 1 and 2:

$2 \mathrm{NaOH}+\mathrm{SiO}_{2}$ (sugarcane ash) $\stackrel{\Delta}{\rightarrow} \mathrm{Na}_{2} \mathrm{SiO}_{3}+\mathrm{H}_{2} \mathrm{O}$
$\mathrm{Na}_{2} \mathrm{SiO}_{3}+2 \mathrm{HCl} \rightarrow \mathrm{SiO}_{2}$ (pure silica) $+2 \mathrm{NaCl}+\mathrm{H}_{2} \mathrm{O}$

The different samples were labeled based on the weight proportion of the reactants utilized in the process of the silicate extraction: 1 ash:0.5 $\mathrm{NaOH}\left(\mathrm{SiO}_{2} \mathrm{NPs} 1: 0.5\right)$; 1 ash:10 NaOH ( $\left.\mathrm{SiO}_{2} \mathrm{NPs} 1: 1.0\right)$; 1 ash:1.5 NaOH $\left(\mathrm{SiO}_{2} \mathrm{NPs} 1: 1.5\right)$ and 1 ash:2 $\mathrm{NaOH}\left(\mathrm{SiO}_{2} \mathrm{NPs} 1: 2.0\right)$. The silica content in sugarcane waste ash is about $77.3 \mathrm{wt} . \%$, thus the silica nanoparticles extraction yield (wt.\%) was calculated using equation $3:{ }^{16}$

wt. $\%=\frac{\text { mass of silica NPs obtained }}{\text { mass of ash utilized } \times 0.773} \times 100$

\section{Characterization}

The chemical composition of sugarcane waste ash and silica nanoparticles were analyzed directly and without any form of treatment, via total X-ray fluorescence spectroscopy (TXRF), using the Bruker PICOFOX S2 equipment, Germany.

Scanning electron microscopy (SEM) images were recorded on a microscope with a field emission gun (FEG-SEM), model JSM-6701F, from JEOL (Japan), at a typical acceleration voltage of $2.0 \mathrm{kV}$. SEM-FEG samples were prepared to deposit, waste ash or silica nanoparticles, dispersed in water, over a polished copper stub.

Transmission electron microscopy (TEM) images were registered using a microscope from JEOL, modelJEM-2100, Japan. TEM samples were prepared to disperse a small amount of sample in water (ca. $\left.1.0 \mathrm{~g} \mathrm{~L}^{-1}\right)$, sonicated in high shear, and then $1 \mu \mathrm{L}$ of the suspension was placed onto a copper grid covered with a thin carbon film and dried in air. 
X-ray diffraction analyses (XRD) were performed using a Rigaku Multiflex diffractometer with a $\mathrm{Cu}$ anode using Co $\mathrm{K} \alpha$ radiation at $40.0 \mathrm{kV}$ and $20.0 \mathrm{~mA}$ over the range

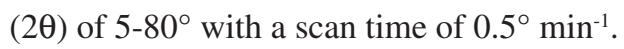

The specific surface area and pore distribution of samples were analyzed using $\mathrm{N}_{2}$ adsorption-desorption isotherms at $-196{ }^{\circ} \mathrm{C}$ using a Micromeritics ASAP 2000 instrument, China.

UV-Vis spectra of the samples were obtained using a Varian spectrophotometer, model Cary 1E (USA), utilizing quartz cuvettes with a $10.0 \mathrm{~mm}$ path length, and scanning samples from 200 to $800 \mathrm{~nm}$.

Fourier-transform infrared (FTIR) spectroscopy was performed using a spectrometer from Bruker, model Alpha (Germany), operating in the attenuated total reflectance (ATR) mode. The spectra of samples were obtained using 200 cumulative scans, in the range of 375 to $4000 \mathrm{~cm}^{-1}$.

Thermogravimetric analyses (TGA) were recorded using a thermogravimetric analyzer TGA/SDTA from Mettler Toledo, Switzerland. Around $10.0 \mathrm{mg}$ was weighed and analyzed in a nitrogen atmosphere with a flow rate of $100.0 \mathrm{~mL} \mathrm{~min}^{-1}$, using an alumina-port sample heated to $1000{ }^{\circ} \mathrm{C}$ with a heating rate of $10^{\circ} \mathrm{C} \mathrm{min}^{-1}$.

\section{Adsorption study}

The isotherm adsorption studies of the MB dye onto $\mathrm{SiO}_{2} \mathrm{NPs}$ were conducted at different initial MB concentrations (from 0 to $100.22 \mathrm{mg} \mathrm{L}^{-1}$ ). Kinetics experiments were carried out agitating the MB solutions with $\mathrm{SiO}_{2} \mathrm{NPs}$ at $190 \mathrm{rpm}$ and an adsorbent dose of $1.0 \mathrm{~g} \mathrm{~L}^{-1}$ for different times from 0 to $360 \mathrm{~min}$ at a constant MB concentration of $40.0 \mathrm{mg} \mathrm{L}^{-1}$. All experiments were performed in triplicate at $25{ }^{\circ} \mathrm{C}$. An analytical curve prepared for the MB is presented in Figure S2 (SI section), the concentration of the MB before and after adsorption was measured using a UV-Vis spectrophotometer.

The equation used for the analytical curve was Abs $=-0.0126+0.16593[\mathrm{MB}]\left(\mathrm{mg} \mathrm{L}^{-1}\right)$ in $\lambda=660 \mathrm{~nm}$, and the value of the coefficient of the adjusted determination $\left(\mathrm{R}_{\text {adj. }}^{2}\right)$ was 0.9976. The amount of MB removal was expressed as the removal percentage of contaminants and calculated using equation 4 :

$\%$ Removal $=\frac{\left(\mathrm{C}_{\mathrm{i}}-\mathrm{C}_{\mathrm{f}}\right)}{\mathrm{C}_{\mathrm{i}}} \times 100$

where $C_{i}$ and $C_{f}$ are the initial and final concentrations of the contaminants, respectively. The amount of contaminant adsorption as a function of time and at equilibrium, $\mathrm{q}_{\mathrm{t}}$, and $\mathrm{q}_{\mathrm{e}}\left(\mathrm{mg} \mathrm{g}^{-1}\right)$, respectively, were calculated using equation 5 : $q_{t}$ or $q_{e}=\frac{\left(C_{i}-C_{e}\right)}{m} \times V$

where $\mathrm{C}_{\mathrm{i}}$ and $\mathrm{C}_{\mathrm{e}}\left(\mathrm{mg} \mathrm{L}^{-1}\right)$ are concentrations of the contaminants at the beginning, the end and at equilibrium, respectively, $\mathrm{V}(\mathrm{L})$ is the volume of the contaminant solution, and $\mathrm{m}(\mathrm{g})$ is the mass of the adsorbent. ${ }^{17}$

The adsorption kinetics of the MB by $\mathrm{SiO}_{2} \mathrm{NPs}$ were tested using pseudo-first-order, pseudo-second-order and general-order ${ }^{18,19}$ nonlinear models. ${ }^{20-22}$ The Langmuir, ${ }^{23}$ Freundlich, ${ }^{24} \mathrm{Liu}^{25}$ and $\mathrm{Sips}^{26}$ nonlinear models were applied to fit the equilibrium data of the $\mathrm{MB}$ by $\mathrm{SiO}_{2} \mathrm{NPs}$. The equations of the nonlinear kinetics, isotherm models and error functions $\left(\mathrm{R}_{\text {adj }}^{2}\right.$, reduced Chi-Square and standard deviation (SD)) are described in the literature. ${ }^{27}$

\section{Results and Discussion}

\section{Characterization of $\mathrm{SiO}_{2} \mathrm{NPs}$}

The synthetic procedure described in this manuscript is, in part, based on previous publications where all characterizations of sugarcane waste ash were reported. ${ }^{12,15}$ In this article the procedure utilized to obtain bare silica nanoparticles and the properties of these nanoparticles are presented.

The silicate was extracted from sugarcane waste ash by mixing the ashes with sodium hydroxide and heating the mixture to $550^{\circ} \mathrm{C}$. Sodium hydroxide melts at temperatures above $320^{\circ} \mathrm{C}$ which increases the interaction with silica in the ash, enhancing the reaction between the hydroxide ions and the silica (initially in crystalline form) and leading to the formation of silicate. The evaluation of this alkaline extraction was performed at four different proportions of ash: $\mathrm{NaOH}$, the yield of these extractions was calculated based on the formatted silica nanoparticles. The results obtained by utilizing the proportions from 1:0.5 to 1:2.0 are presented in Table 1 below.

Table 1. Yield of silica nanoparticles extractions

\begin{tabular}{lcccc}
\hline Ash:NaOH (w:w) & $1: 0.5$ & $1: 1$ & $1: 1.5$ & $1: 2$ \\
\hline Yield / wt.\% & 35.33 & 74.68 & 95.45 & 95.94 \\
\hline
\end{tabular}

In Table 1, it is possible to observe that the extraction yield increases from $35.33 \%$ for the 1:0.5 (ash:NaOH) mixture to $95.94 \%$ for the $1: 2$ (ash: $\mathrm{NaOH}$ ) mixture, however it is possible to see that in the 1:1.5 ratio, the yield is already above $95 \%$. This indicates an increase of less than $0.5 \%$ for an increase of 0.5 times in the proportion of $\mathrm{NaOH}$, the maximum extraction capacity of this 
method was reached at the 1:1.5 (ash:NaOH) proportion. Analyzing equation 1, the theoretical value necessary for a total extraction based on w:w, should be a proportion of 1:1.33 (ash:NaOH) for a pure sample regarding the $\mathrm{SiO}_{2}$ quantity. This larger quantity that is necessary can be due to an increased difficulty to extract silica when it is present in a crystalline form, and also due to the presence of other elements capable of reacting with the hydroxide ions, like iron and aluminum. ${ }^{12}$

Figure 1 shows the XRD diffractograms of the $\mathrm{SiO}_{2} \mathrm{NPs}$ obtained with different ratios of ash:NaOH. Different from sugarcane waste ash which only presents crystalline silica that is mainly assigned to peaks present in the quartz form, ${ }^{12,15}$ (Figure S3, SI section), the diffractograms of silica nanoparticles for the synthesized samples indicate the presence of amorphous silica only which is characterized by the presence of a broad single peak, reaching its maximum at $22^{\circ}(2 \theta)$, corroborating with examples in the literature. ${ }^{13,14,16,28}$ The absence of crystalline peaks in the structure does not allow the Scherrer equation to be utilized for the calculation of the crystallite size.

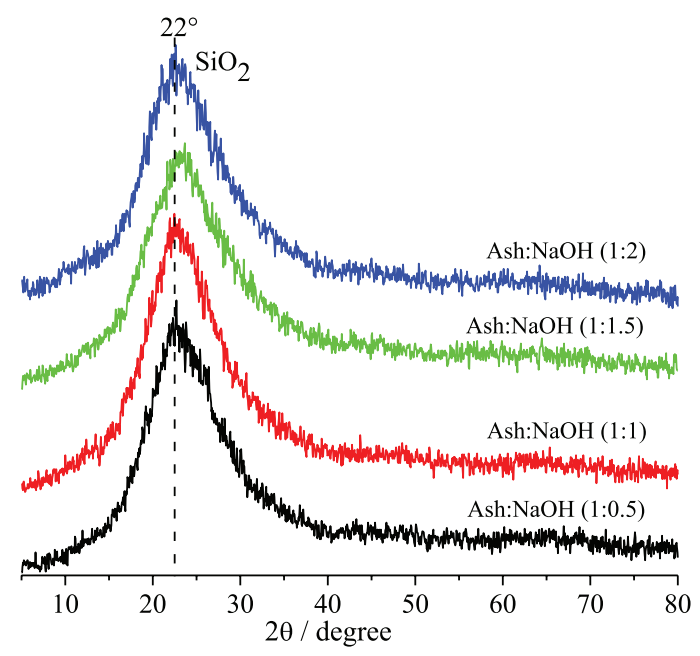

Figure 1. XRD patterns of the silica nanoparticles samples.

Another important observation is that the absence of the crystalline phase in the material indicate the absence of impurities, such as $\mathrm{NaCl}$, or crystalline unreacted silica. It is possible to conclude that the samples have the same structural and spectroscopic characteristics, which suggest that only the yield is affected when the sodium hydroxide quantity is increased. This is an important observation with regards to the properties and future applications.

Aiming to detect the presence of organic compounds on the surface of $\mathrm{SiO}_{2} \mathrm{NPs}$, all samples were also analyzed by FTIR using ATR mode, as can be seen in Figure 2, below.

The infrared spectra were recorded in the range of $4000-375 \mathrm{~cm}^{-1}$, and it is possible to observe that all samples

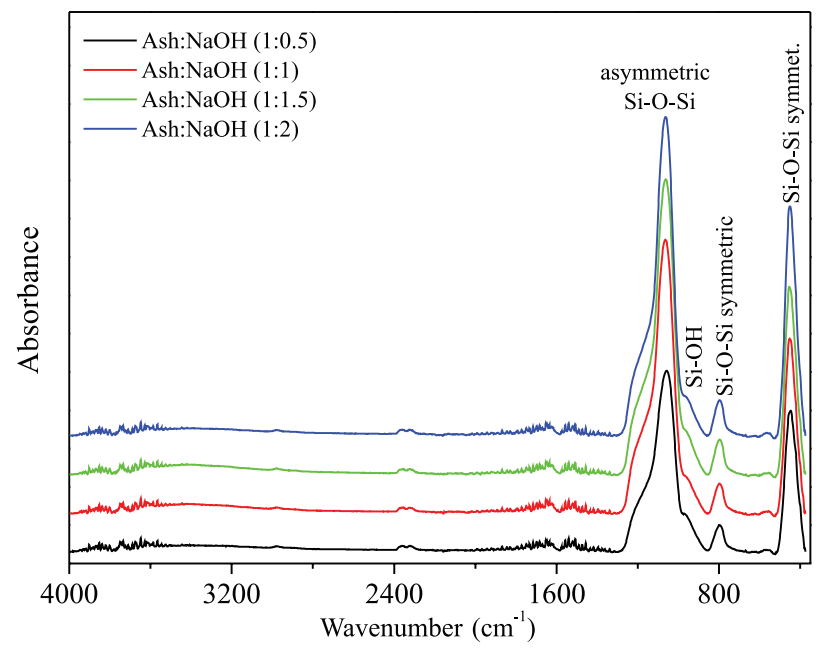

Figure 2. FTIR (ATR) spectra of the silica nanoparticles samples.

are very similar, only observing the characteristic peaks of the silica in all the samples. The peaks at 450 and $798 \mathrm{~cm}^{-1}$ can be assigned as symmetric stretching of siloxane groups ( $\mathrm{Si}-\mathrm{O}-\mathrm{Si}$ ), as well as the peak at $1060 \mathrm{~cm}^{-1}$, an asymmetric stretching of these groups. The shoulder around $960 \mathrm{~cm}^{-1}$ is related to the angular deformation $\mathrm{Si}-\mathrm{OH}$ of the silanol group. ${ }^{4,29}$ The FTIR spectra indicate that none of the samples have (or have in very low concentrations, undetectable by this technique) organic molecules on their surface, indicating that the samples are bare or have low concentrations of molecules on their surface. This is very interesting since organic molecules, especially ones that contain carboxylates, are difficult to remove from metallic oxides, even after treatment with peroxides or other oxidative species. ${ }^{30}$

This low presence of organic molecules is confirmed by TGA analyses performed in a nitrogen atmosphere, presented in Figure 3, below.

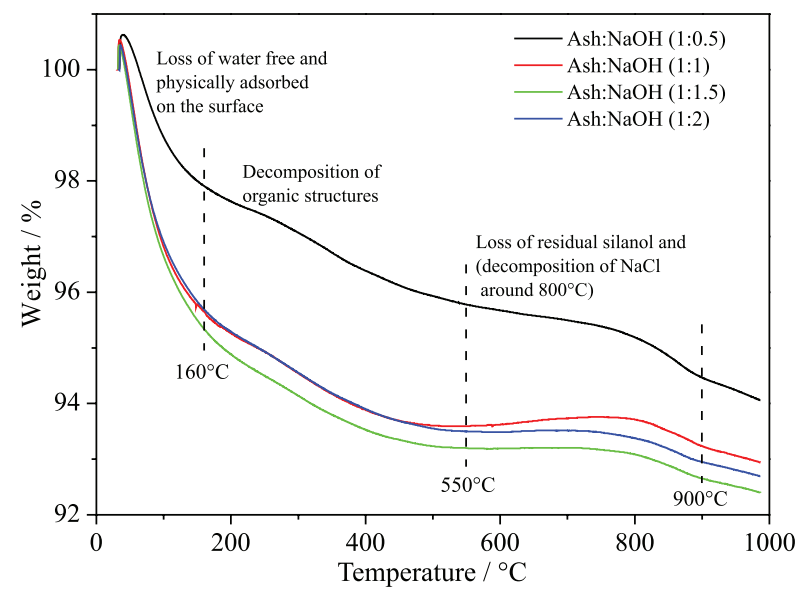

Figure 3. TG curves of the silica nanoparticle samples. The measures were performed under $\mathrm{N}_{2}$. 
Analyzing the thermogravimetric (TG) curves, it is possible to observe a mass loss behavior similar in all samples and observing the presence of three different processes. In the first stage of the thermoanalysis (until $180^{\circ} \mathrm{C}$ ), a loss attributed to moisture occurred and the water physically adsorbed to the surface. The second mass loss, between $180-550^{\circ} \mathrm{C}$, can be assigned to the decomposition of possible remaining organic structures. This loss is equal in all samples, evident when the inclination of the four curves was analyzed..$^{31}$ The third decomposition stage, between $550-900{ }^{\circ} \mathrm{C}$, is due to the loss of residual silanol and the decomposition of $\mathrm{NaCl}$ around $800{ }^{\circ} \mathrm{C} .{ }^{16}$ Above $900{ }^{\circ} \mathrm{C}$ the loss of mass can be attributed to the surface dehydroxylation reaction in all samples. ${ }^{31} \mathrm{TG}$ and derivative thermogravimetric analysis (DTG) curves of the sugarcane waste ash are shown in Figure S4 (SI section).

Analyzing the samples individually, it is possible to see that the sample $\mathrm{SiO}_{2} \mathrm{NPs}(1: 0.5)$ has less water adsorbed to its surface than the other samples (loss until $100{ }^{\circ} \mathrm{C}$ ). Although the drying process had been applied equally for all samples, the smaller quantity of sample generated (due to lower yield) made it easier to dry the sample, however this difference is only about $2 \%$ for $\mathrm{SiO}_{2} \mathrm{NPs}(1: 0.5)$ and the other samples. On the other hand, the loss of organic material is almost the same, which could be seen in the parallelism of the curves where all samples loss around $2 \%$ of the organic material, thus presenting a very low quantity of organic material, as already reported when FTIR analyses were conducted.

In the third process, the samples presented different behaviors due to different quantities of $\mathrm{NaCl}$. The sample with the 1:0.5 proportion presented a lower quantity of $\mathrm{NaCl}$. The samples with the 1:1.0, 1:1.5 and 1:2.0 proportions presented roughly the same quantities of $\mathrm{NaCl}$. This fact can also be explained by the differences in the washing processes of the samples. However, it was possible to see that all samples had less than $1.0 \%$ of $\mathrm{NaCl}$. The results obtained in the TG are in agreement with the data reported by the analysis of infrared vibrational spectra (see Figure 2), where all samples showed the presence of a low quantity of organic material and a material with composition of only one inorganic material.

Considering the similarity of the samples observed by XRD, FTIR and TGA, the sample $\mathrm{SiO}_{2} \mathrm{NPs}(1: 1.5)$ was chosen to be explored further with regards to morphology, composition, superficial area and adsorption capacity, since it is possible to observe the samples with higher yield and lower quantity of sodium hydroxide needs for silica extraction. Different magnifications of SEM and TEM images of the $\mathrm{SiO}_{2} \mathrm{NPs}(1: 1.5)$ sample are presented in
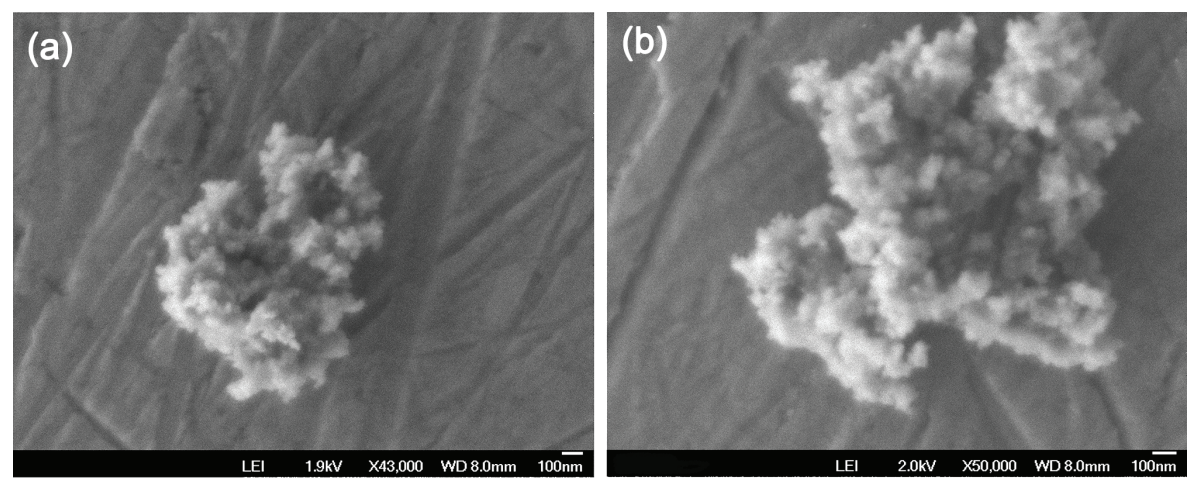

(c)

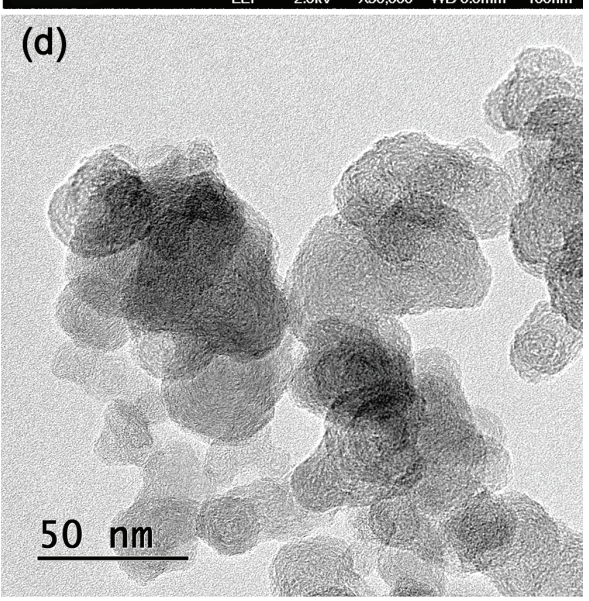

Figure 4. SEM images of the $\mathrm{SiO}_{2} \mathrm{NPs}$ 1:1.5 sample (a-b) with two different magnifications and TEM images (c-d) with two different magnifications. See more SEM and TEM images in Figures S5, S6 and S7 (SI section). 


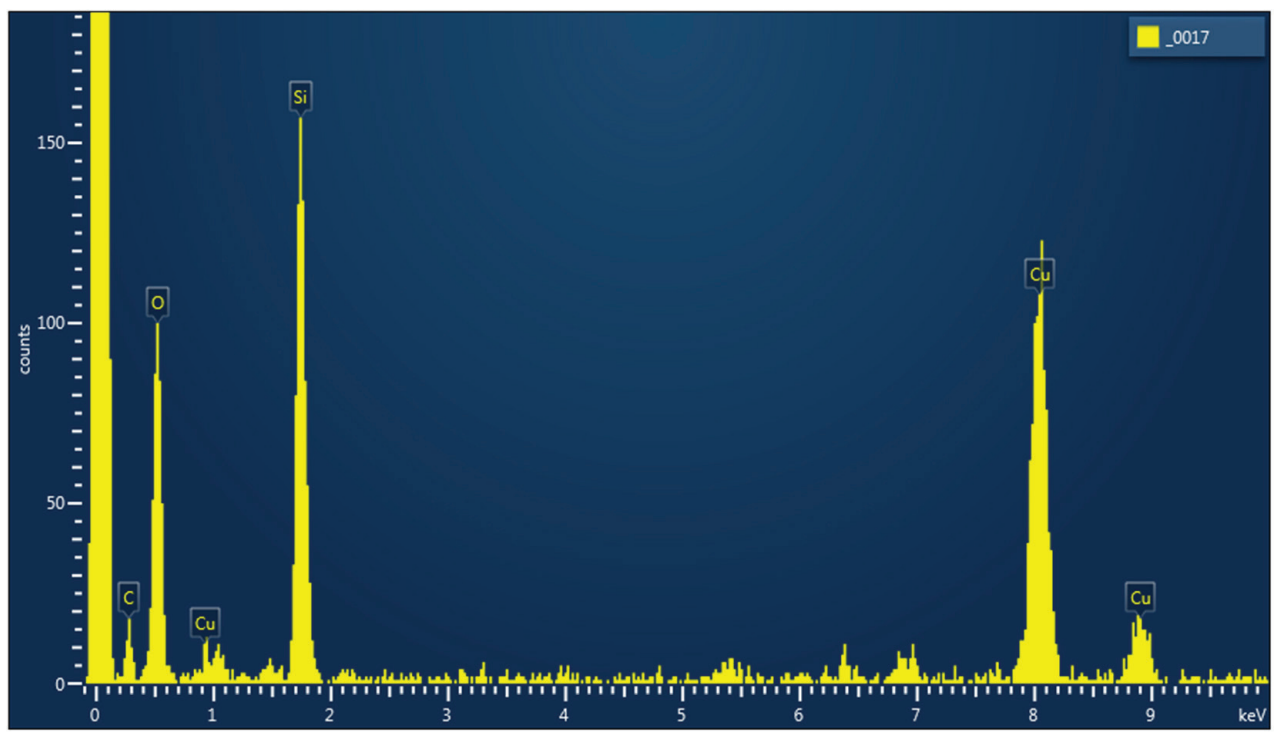

Figure 5. EDS of the $\mathrm{SiO}_{2} \mathrm{NPs}$ 1:1.5 sample (Cu signal comes from TEM grid).

Figure 4. An energy-dispersive X-ray spectroscopy (EDS) spectrum of this same sample is presented in Figure 5.

The images confirm the presence of irregular quasi-spherical silica nanoparticles, with a size smaller than $100 \mathrm{~nm}$. It is also observed that the nanoparticles formed aggregates of several nanoparticles, especially due to the absence of stabilizer molecules, however it was in fact possible to observe their individualities by looking at the boards presented in the microscopy.

The EDS spectrum of the $\mathrm{SiO}_{2} \mathrm{NPs}$ (1:1.5) sample, presented in Figure 5, showed only the presence of oxygen (at $0.5 \mathrm{keV}$ ) and silicon (at $1.7 \mathrm{keV}$ ) as main peaks (the $\mathrm{Cu}$ signal observed is due to the grid utilized to perform the measurements), however the composition of the elements determined by TXRF (Table 2) showed the presence of other elements in a lower quantity. The composition of sugarcane waste ash is shown in Table 2.

Table 2. Total reflection X-ray fluorescence (TRXRF) of sugarcane waste ash and silica nanoparticles

\begin{tabular}{lcc}
\hline Element & Sugarcane ash / wt. $\%$ & $\mathrm{SiO}_{2} \mathrm{NPs} 1: 1.5 /$ wt. $\%$ \\
\hline $\mathrm{Si}$ & 77.32 & 94.89 \\
$\mathrm{Al}$ & 4.10 & 1.67 \\
$\mathrm{Fe}$ & 8.64 & 2.57 \\
$\mathrm{~K}$ & 4.22 & 0.13 \\
$\mathrm{Ca}$ & 2.00 & 0.13 \\
$\mathrm{Ti}$ & 1.55 & 0.40 \\
Others & 2.17 & 0.21 \\
\hline
\end{tabular}

It was possible to observe a significant increase in the purity of the material where a Si content of 77.32 wt.\% for sugarcane waste ash increased to $94.89 \mathrm{wt} . \%$ for the $\mathrm{SiO}_{2} \mathrm{NPs}$ (1:1.5) sample. As a consequence, the content of Al decreased from 4.10 (ash) to 1.67 wt.\% ( $\left.\mathrm{SiO}_{2} \mathrm{NPs} 1: 1.5\right)$, Fe decreased from 8.64 (ash) to 2.57 wt.\% ( $\left.\mathrm{SiO}_{2} \mathrm{NPs} 1: 1.5\right)$, K decreased from 4.22 (ash) to 0.13 wt. $\%\left(\mathrm{SiO}_{2} \mathrm{NPs} 1: 1.5\right)$, the Ca content decreased from 2.00 (ash) to $0.13 \mathrm{wt} . \%\left(\mathrm{SiO}_{2} \mathrm{NPs}_{1: 1.5)}\right.$ and

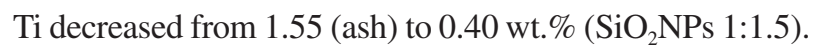
These results indicate that the process of extraction can also purify the material resulting in high purity silica. The observed decrease in $\mathrm{Fe}$ and $\mathrm{Al}$ helps the future utilization of these nanoparticles as supports for catalysts. ${ }^{32}$

The surface area and porosity of the material were analyzed by using a $\mathrm{N}_{2}$ adsorption/desorption isotherm for the $\mathrm{SiO}_{2} \mathrm{NPs}$ (1:1.5) sample. The Brunauer-Emmett-Teller (BET) analysis and the textural properties are reported in Figure 6 and Table 3, respectively.

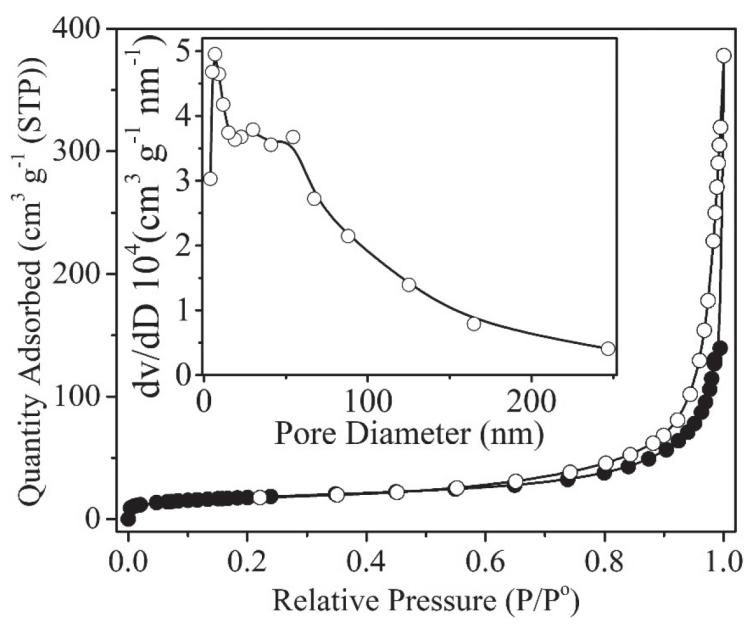

Figure 6. The $\mathrm{N}_{2}$ adsorption/desorption isotherm of the silica nanoparticles ( adsorption and $\bigcirc$ desorption) for the $\mathrm{SiO}_{2} \mathrm{NPs}$ 1:1.5 sample. Insert: pore size distribution. 
Table 3. Experimental textural properties of the $\mathrm{SiO}_{2} \mathrm{NPs} 1: 1.5$ sample

\begin{tabular}{lccc}
\hline Sample & $\begin{array}{c}\text { Surface area } \\
\left(\mathrm{m}^{2} \mathrm{~g}^{-1}\right)\end{array}$ & $\begin{array}{c}\text { Pore diameter } / \\
\mathrm{nm}\end{array}$ & $\begin{array}{c}\text { Pore volume } \\
\left(\mathrm{cm}^{3} \mathrm{~g}^{-1}\right)\end{array}$ \\
\hline Silica & 63 & 33 & 0.47 \\
\hline
\end{tabular}

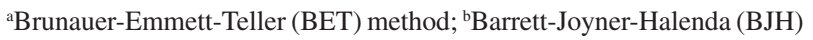
method.

The textural properties of the sugarcane waste ash has already been reported in a previous article,$^{12}$ thus only the results of the $\mathrm{SiO}_{2} \mathrm{NPs}$ are presented. The $\mathrm{SiO}_{2} \mathrm{NPs}(1: 1.5)$ sample isotherm can be classified as Type $\mathrm{IIb},{ }^{33}$ which is associated with aggregates of plate-like particles with non-rigid, slit-shaped pores, resulting in large pore size distribution. The absence of the plateau in the $\mathrm{P} / \mathrm{P}^{\circ}$ close to 1 served as evidence for the presence of a macropore and the hysteresis loop observed between the adsorption-desorption branches is related to the presence of a mesopore..$^{34}$ Thus, the mesoporous structure was evaluated through the Barrett-Joyner-Halenda (BJH) method (insert in Figure 6).

The pore size distribution between 2 and $50 \mathrm{~nm}$, and the distribution of pores sizes above $50 \mathrm{~nm}$ (insert in Figure 6) indicated the presence of a mesopore and a macropore, respectively. ${ }^{35}$ The average pore diameter of the $\mathrm{SiO}_{2} \mathrm{NPs}$ 1:1.5 sample was $33 \mathrm{~nm}$ (mesoporous materials) as shown in Table 3. The surface area and the pore volume of the $\mathrm{SiO}_{2} \mathrm{NPs}$ 1:1.5 sample were $63 \mathrm{~m}^{2} \mathrm{~g}^{-1}$ and $0.47 \mathrm{~cm}^{3} \mathrm{~g}^{-1}$, respectively. We obtained $\mathrm{SiO}_{2} \mathrm{NPs}$ with a surface area more than 2.8 times larger than that obtained by Bhakta et al.$^{36}$ for the Stober-NPs sample. These results showed an increase in the superficial area (sugarcane waste ash has a surface area of $5 \mathrm{~m}^{2} \mathrm{~g}^{-1}$ ) of more than 12 times, which is considered a very important aspect in the application of adsorbents.

\section{Adsorption study}

The kinetics of the adsorption, the adsorption capacity and the mechanism of adsorption to the prepared silica nanoparticles were evaluated utilizing a MB dye. This molecule is a valid model for this type of study since several previously reported studies have used it, thus enabling the comparison of this adsorbent with others in the literature. ${ }^{37-40}$ Figure 7 shows the variation of the amount of MB adsorbed ( $\mathrm{q}_{\mathrm{t}}$ ) onto $\mathrm{SiO}_{2} \mathrm{NPs}$ 1:1.5 as a function of time and Table 4 resumes the parameters for pseudo-first-order, pseudo-second-order and general-order kinetic models.

Considering solely the experimental points, it was possible to observe that $\mathrm{MB}$ adsorption occurs very fast during the first $10 \mathrm{~min}$, and saturation occurs after $100 \mathrm{~min}$. According to the kinetic models, the pseudo-second-order and general-order models presented a slightly better fit to the experimental data as compared to the pseudo-first-order

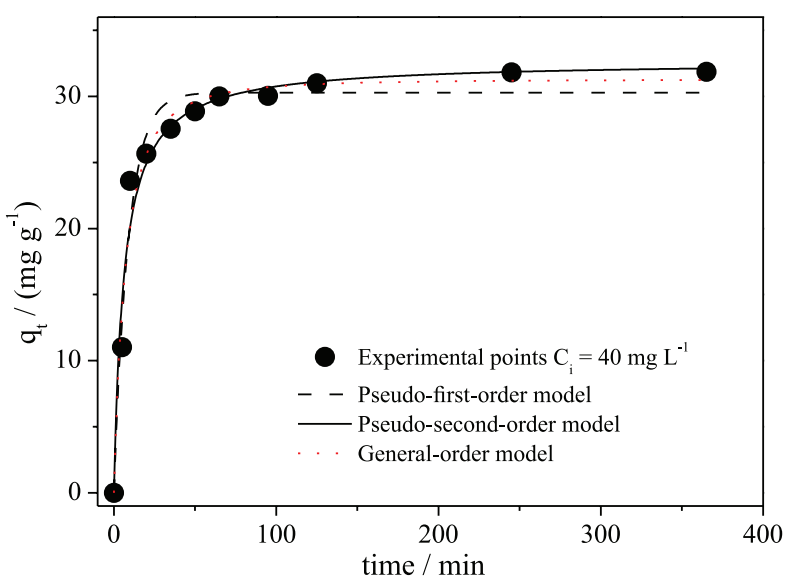

Figure 7. Pseudo-first, second-order and general-order model kinetics plot for the removal of $\mathrm{MB}$ with the $\mathrm{SiO}_{2} \mathrm{NPs} 1: 1.5$ adsorbent $\left(\mathrm{T}=25^{\circ} \mathrm{C}\right.$; $\mathrm{C}_{\mathrm{i}}=40.0 \mathrm{mg} \mathrm{L}^{-1}$, adsorbent dose $\left.=1.0 \mathrm{~g} \mathrm{~L}^{-1}\right)$. See UV-Vis spectra before and after MB adsorption in Figure S8 (SI section).

Table 4. Kinetic parameters for $\mathrm{MB}$ adsorption onto $\mathrm{SiO}_{2} \mathrm{NPs}$ 1:1.5

\begin{tabular}{|c|c|}
\hline \multicolumn{2}{|c|}{ Pseudo-first-order } \\
\hline $\mathrm{k}_{\mathrm{f}} / \min ^{-1}$ & 0.1123 \\
\hline $\mathrm{q}_{\mathrm{e}} /\left(\mathrm{mg} \mathrm{g}^{-1}\right)$ & 30.28 \\
\hline $\mathrm{R}_{\text {adj. }}^{2}$ & 0.9698 \\
\hline Reduced Chi-squared & 3.091 \\
\hline $\mathrm{SD} /\left(\mathrm{mg} \mathrm{g}^{-1}\right)$ & 1.758 \\
\hline \multicolumn{2}{|c|}{ Pseudo-second-order } \\
\hline $\mathrm{k}_{\mathrm{s}} /\left(\mathrm{g} \mathrm{mg}^{-1} \mathrm{~min}^{-1}\right)$ & 0.00493 \\
\hline $\mathrm{q}_{\mathrm{e}} /\left(\mathrm{mg} \mathrm{g}^{-1}\right)$ & 32.66 \\
\hline $\mathrm{R}_{\text {adj. }}^{2}$ & 0.9720 \\
\hline Reduced Chi-squared & 2.861 \\
\hline $\mathrm{SD} /\left(\mathrm{mg} \mathrm{g}^{-1}\right)$ & 1.691 \\
\hline \multicolumn{2}{|c|}{ General-order } \\
\hline $\mathrm{k}_{\mathrm{N}} /\left[\mathrm{min}^{-1}\left(\mathrm{~g} \mathrm{mg}^{-1}\right)^{\mathrm{n}-1}\right]$ & 0.0233 \\
\hline $\mathrm{q}_{\mathrm{e}} /\left(\mathrm{mg} \mathrm{g}^{-1}\right)$ & 31.29 \\
\hline $\mathrm{n}$ & 1.514 \\
\hline $\mathrm{R}_{\text {adj. }}^{2}$ & 0.9723 \\
\hline Reduced Chi-squared & 2.833 \\
\hline $\mathrm{SD} /\left(\mathrm{mg} \mathrm{g}^{-1}\right)$ & 1.683 \\
\hline
\end{tabular}

$\mathrm{k}_{\mathrm{f}}$ : pseudo-first-order adsorption rate constant; $\mathrm{q}_{\mathrm{e}}$ : equilibrium adsorption capacity; $\mathrm{R}_{\text {adj: }}^{2}$ : adjusted coefficient of determination; $\mathrm{SD}$ : standard deviation; $\mathrm{k}_{\mathrm{s}}$ : pseudo-second-order adsorption rate constant; $\mathrm{k}_{\mathrm{N}}$ : generalorder adsorption rate constant; $\mathrm{n}$ : order of adsorption with respect to the effective concentration of the adsorption active sites present on the surface of adsorbent.

model. However, the general-order model presented an adjusted coefficient of determination $\left(\mathrm{R}_{\text {adj. }}^{2}\right)$ value the closest to 1 and the lowest values of reduced Chi-square and SD. This suggests a smaller disparity between the calculated $\mathrm{q}_{\mathrm{e}}$ values and the experimental values, therefore, the $\mathrm{q}_{\mathrm{e}}$ value $\left(31.29 \mathrm{mg} \mathrm{g}^{-1}\right)$ predicted by the general-order model was the closest one to the experimental $\mathrm{q}_{\mathrm{e}}$ value (30.95 $\mathrm{mg} \mathrm{g}^{-1}$ ) (see Table 4). 
The kinetic model of general-order predicted that the order of an adsorption process should follow the same trend as a chemical reaction, where the order of the reaction is obtained experimentally. Since the order of reaction of the adsorption process cannot be predicted theoretically, it is not appropriate to predetermine the order of adsorption kinetics as being of the first or second order, unless the adsorption mechanisms are well known. However, little or nothing is known about the reaction mechanisms, due to the fact that the adsorption process is extremely complex and several mechanisms may be involved. This fast association of the adsorbate to the adsorbent is very important for the utilization of this material for the remediation of water bodies, as well as for the utilization as filters or other adsorbent applications. ${ }^{41}$

The adsorption isotherms describe the relationship between $\mathrm{q}_{\mathrm{e}}$ and $\mathrm{C}_{\mathrm{e}}$ at a constant temperature. The comparison of nonlinear fitted curves from experimental data and Langmuir, Freundlich, Liu and Sips isotherm models are shown in Figure 8 below. The coefficients of determination and the isotherm parameters from the nonlinear regressive method are listed in Table 5.

According to Figure 8 and Table 5, the Langmuir adsorption nonlinear model was the one that best fitted the experimental data agreeing with the value of $\mathrm{R}_{\text {adj. }}^{2}$ closer to 1 as compared to the value of $\mathbf{R}_{\text {adj. }}^{2}$ of the Freundlich, Liu and Sips model. This suggests that the adsorption of MB dye molecules onto $\mathrm{SiO}_{2} \mathrm{NPs}$ 1:1.5 occurs in a monolayer in a finite number of adsorption sites. Moreover, presented the lowest value of reduced Chi-square and SD, and the monolayer maximum adsorption capacity calculated from the Langmuir isotherm is $37.3 \mathrm{mg} \mathrm{g}^{-1}$, which approaches the experimental data $\left(36.7 \mathrm{mg} \mathrm{g}^{-1}\right)$. This is an expected result since these nanoparticles are bare and the only possible interaction is the electrostatic interaction between the negative charges on the surface of the silica nanoparticles and the positive charge of MB. ${ }^{40,42-47}$ This way this type of interaction can only generate a single layer of molecules on the surface of the nanoparticles, and after the neutralization of the surface, there is a saturation of the surface.

According to the literature, ${ }^{39,44}$ meso and macropores facilitate the transport of dye molecules to the adsorption sites of the adsorbent. A positive effect was observed in this study where the pore size distribution (meso and macropores) of $\mathrm{SiO}_{2} \mathrm{NPs}$ facilitated the adsorption of the MB molecule that have a size of $1.43 \mathrm{~nm}$ in length and $0.61 \mathrm{~nm}$ in height. ${ }^{39}$

\section{Conclusions}

Silica nanoparticles were successfully synthesized from sugarcane waste ash. The yield of the $\mathrm{SiO}_{2} \mathrm{NPs}$

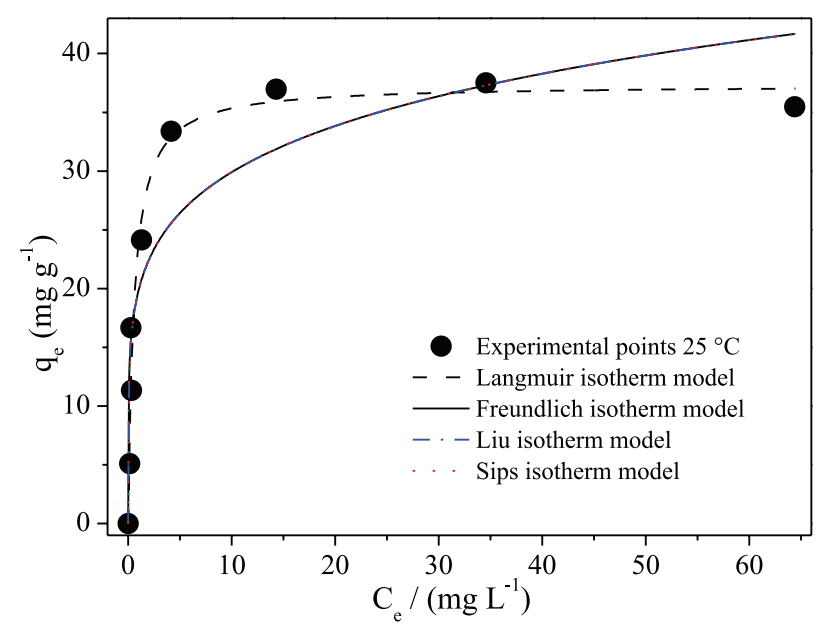

Figure 8. Adsorption Langmuir, Freundlich, Liu and Sips isotherm models for the removal of $\mathrm{MB}$ via the usage of the $\mathrm{SiO}_{2} \mathrm{NPs}$ 1:1.5 adsorbent $\left(\mathrm{T}=25^{\circ} \mathrm{C}\right.$; adsorbent dose $=1.0 \mathrm{~g} \mathrm{~L}^{-1}$, contact time $\left.=2 \mathrm{~h}\right)$. See UV-Vis spectra before and after MB adsorption at equilibrium time in Figures $\mathrm{S} 9$ and S10 (SI section).

Table 5. Parameters isotherm models for MB adsorption onto $\mathrm{SiO}_{2} \mathrm{NPs}$ 1:1.5

\begin{tabular}{|c|c|}
\hline \multicolumn{2}{|c|}{ Langmuir } \\
\hline $\mathrm{Q}_{\max } /\left(\mathrm{mg} \mathrm{g}^{-1}\right)$ & 37.34 \\
\hline $\mathrm{K}_{\mathrm{L}} /\left(\mathrm{L} \mathrm{mg}^{-1}\right)$ & 1.768 \\
\hline $\mathrm{R}_{\text {adj. }}^{2}$ & 0.9734 \\
\hline Reduced Chi-squared & 5.631 \\
\hline $\mathrm{SD} /\left(\mathrm{mg} \mathrm{g}^{-1}\right)$ & 2.368 \\
\hline \multicolumn{2}{|c|}{ Freundlich } \\
\hline $\mathrm{K}_{\mathrm{F}} /\left(\left(\mathrm{mg} \mathrm{g}^{-1}\right)\left(\mathrm{L} \mathrm{mg}^{-1}\right)^{1 / \mathrm{FF}}\right)$ & 19.85 \\
\hline $\mathrm{n}_{\mathrm{F}}$ & 5.615 \\
\hline $\mathrm{R}_{\text {adj. }}^{2}$ & 0.8383 \\
\hline Reduced Chi-squared & 34.21 \\
\hline $\mathrm{SD} /\left(\mathrm{mg} \mathrm{g}^{-1}\right)$ & 5.849 \\
\hline \multicolumn{2}{|c|}{ Liu } \\
\hline $\mathrm{Q}_{\max } /\left(\mathrm{mg} \mathrm{g}^{-1}\right)$ & 12.93 \\
\hline $\mathrm{K}_{\mathrm{g}} /\left(\mathrm{L} \mathrm{mg}^{-1}\right)$ & 7.307 \\
\hline $\mathrm{n}_{\mathrm{L}}$ & 0.1781 \\
\hline $\mathrm{R}_{\text {adj. }}^{2}$ & 0.8113 \\
\hline Reduced Chi-squared & 39.92 \\
\hline $\mathrm{SD} /\left(\mathrm{mg} \mathrm{g}^{-1}\right)$ & 6.318 \\
\hline \multicolumn{2}{|c|}{ Sips } \\
\hline $\mathrm{Q}_{\max } /\left(\mathrm{mg} \mathrm{g}^{-1}\right)$ & 2.084 \\
\hline $\mathrm{K}_{\mathrm{S}} /\left(\mathrm{mg} \mathrm{L}^{-1}\right)^{-1 / n \mathrm{~s}}$ & 6.436 \\
\hline $\mathrm{n}_{\mathrm{S}}$ & 5.615 \\
\hline $\mathrm{R}_{\text {adj. }}^{2}$ & 0.8113 \\
\hline Reduced Chi-squared & 39.92 \\
\hline $\mathrm{SD} /\left(\mathrm{mg} \mathrm{g}^{-1}\right)$ & 6.318 \\
\hline \multicolumn{2}{|c|}{$\begin{array}{l}\mathrm{Q}_{\max }: \text { maximum amount adsorbed; } \mathrm{K}_{\mathrm{L}}: \text { Langmuir equilibrium } \\
\text { constant; } \mathrm{R}_{\text {adj. }}^{2}: \text { adjusted coefficient of determination; } \mathrm{SD} \text { : standard } \\
\text { deviation; } \mathrm{K}_{\mathrm{F}}: \text { Freundlich equilibrium constant; } \mathrm{n}_{\mathrm{F}}: \text { dimensionless } \\
\text { exponent of the Freundlich equation; } \mathrm{K}_{\mathrm{g}}: \text { Liu equilibrium constant; } \\
\mathrm{n}_{\mathrm{L}}: \text { dimensionless exponent of the Liu equation; } \mathrm{K}_{\mathrm{s}}: \text { Sips equilibrium } \\
\text { constant; } \mathrm{n}_{\mathrm{s}}: \text { dimensionless exponent of the Sips equation. }\end{array}$} \\
\hline
\end{tabular}


extraction was above $95 \%$ and remained constant at an ash: $\mathrm{NaOH}$ ratio of $1: 1.5$. The $\mathrm{SiO}_{2} \mathrm{NPs} 1: 1.5$ samples were characterized by SEM and TEM, which showed the presence of small nanoparticles $(<100 \mathrm{~nm})$. In addition, the BET method was also applied in which the nanoparticles presented a specific surface area of $63 \mathrm{~m}^{2} \mathrm{~g}^{-1}$ and the coexistence of mesopores and macropores. The $\mathrm{SiO}_{2} \mathrm{NPs}$ 1:1.5 adsorbent was applied to adsorb the MB dye from an aqueous solution and the kinetic model that best predicted the adsorption kinetics was found to be the pseudo-second-order model. The Langmuir isotherm best predicted the experimental data, indicating that $\mathrm{MB}$ adsorbed to $\mathrm{SiO}_{2} \mathrm{NPs}$, forming a monolayer. The adsorbent showed maximum adsorption capacity around $37 \mathrm{mg} \mathrm{g}^{-1}$ as well. The results indicate that it was possible to obtain a desired adsorbent from a renewable source, with a low cost and with an easy and fast synthesis procedure.

\section{Supplementary Information}

Supplementary data (scheme of preparation of sodium silicate solution and synthesis of silica nanoparticles; UVVis spectra of methylene blue and the analytical curve; XRD patterns of the sugarcane waste ash; TG and DTG curves of the sugarcane waste ash; SEM images of sugarcane waste ash, $\mathrm{SiO}_{2} \mathrm{NPs}_{1} 1: 0.5, \mathrm{SiO}_{2} \mathrm{NPs} 1: 1, \mathrm{SiO}_{2} \mathrm{NPs}_{1} 1: 1.5$ and $\mathrm{SiO}_{2}$ NPs 1:2; TEM images of the $\mathrm{SiO}_{2} \mathrm{NPs} 1: 1.5$; UV-Vis spectra before and after methylene blue adsorption; UV-Vis spectra before and after $\mathrm{MB}$ adsorption at equilibrium time of $2 \mathrm{~h}$ and images of samples of methylene blue adsorption at equilibrium time $2 \mathrm{~h}$ ) are available free of charge at http://jbcs.sbq.org.br as a PDF file.

\section{Acknowledgments}

We would like to thank FAPESP (Fundação de Amparo à Pesquisa do Estado de São Paulo) for financial support. We would also like to thank Dr Ricardo Couto and Profa Vera R. L. Constantino, from IQ-USP for carrying out the BET analyses, Dra Duclerc F. Parra for the TGA analyses and Dra Nilce Ortiz who made the UV-Vis spectrophotometer to collect UV-Vis spectra available and COSAN S.A. (São Paulo, Brazil) for supplying the sugarcane waste ash. This study was financed in part by the Coordenação de Aperfeiçoamento de Pessoal de Nível Superior-Brasil (CAPES)-Finance Code 001.

\section{References}

1. Companhia Nacional de Abastecimento (CONAB); Acompanhamento da Safra Brasileira: Cana-de-Açúcar: Safra
2017/2018, 4 Levantamento; available at https://www.conab. gov.br/info-agro/safras/cana accessed on August 6, 2018.

2. Norsuraya, S.; Fazlena, H.; Norhasyimi, R.; Procedia Eng. 2016, $148,839$.

3. Vaibhav, V.; Vijayalakshmi, U.; Roopan, S. M.; Spectrochim. Acta, Part A 2015, 139, 515.

4. Boza, A. F.; Kupfer, V. L.; Oliveira, A. R.; Radovanovic, E.; Rinaldi, A. W.; Meneguin, J. G.; Domingues, N. L. C.; Moisés, M. P.; Favaro, S. L.; RSC Adv. 2016, 6, 23981.

5. Arumugam, A.; Ponnusami, V.; J. Sol-Gel Sci. Technol. 2013, $67,244$.

6. Wang, Y.; Kalinina, A.; Sun, T.; Nowack, B.; Sci. Total Environ. 2016, 545-546, 67.

7. Haldimann, M.; Luible, A.; Overend, M.; Structural Use of Glass; Structural Engineering Documents; International Association for Bridge and Structural Engineering: Zurich, 2008.

8. Kyzas, G.; Kostoglou, M.; Materials 2014, 7, 333.

9. Chen, F.; Zhao, E.; Kim, T.; Wang, J.; Hableel, G.; Reardon, P. J. T.; Ananthakrishna, S. J.; Wang, T.; Arconada-Alvarez, S.; Knowles, J. C.; Jokerst, J. V.; ACS Appl. Mater. Interfaces 2017, 9, 15566 .

10. Mahmoodi, N. M.; Maghsoudi, A.; Najafi, F.; Jalili, M.; Kharrati, H.; Desalin. Water Treat. 2014, 52, 7784.

11. Nayab, S.; Farrukh, A.; Oluz, Z.; Tuncel, E.; Tariq, S. R.; ur Rahman, H.; Kirchhoff, K.; Duran, H.; Yameen, B.; ACS Appl. Mater. Interfaces 2014, 6, 4408.

12. Rovani, S.; Santos, J. J.; Corio, P.; Fungaro, D. A.; ACS Omega 2018, 3, 2618.

13. Rafiee, E.; Shahebrahimi, S.; Feyzi, M.; Shaterzadeh, M.; Int. Nano Lett. 2012, 2, 29.

14. Hassan, A. F.; Abdelghny, A. M.; Elhadidy, H.; Youssef, A. M.; J. Sol-Gel Sci. Technol. 2014, 69, 465.

15. Alves, R. H.; Reis, T. V. D. S.; Rovani, S.; Fungaro, D. A.; J. Chem. 2017, 2017, ID 6129035.

16. Liou, T.-H.; Yang, C.-C.; Mater. Sci. Eng., B 2011, 176, 521.

17. Rovani, S.; Rodrigues, A. G.; Medeiros, L. F.; Cataluña, R.; Lima, É. C.; Fernandes, A. N.; J. Environ. Chem. Eng. 2016, 4, 2128.

18. Liu, Y.; Shen, L.; Biochem. Eng. J. 2008, 38, 390.

19. Alencar, W. S.; Lima, E. C.; Royer, B.; dos Santos, B. D.; Calvete, T.; da Silva, E. A.; Alves, C. N.; Sep. Sci. Technol. 2012, 47, 513.

20. Lagergren, S.; K. Sven. Vetenskapsakad. Handl. 1898, 24, 1.

21. Ho, Y. S.; McKay, G.; Chem. Eng. J. 1998, 70, 115.

22. Blanchard, G.; Maunaye, M.; Martin, G.; Water Res. 1984, 18, 1501.

23. Langmuir, I.; J. Am. Chem. Soc. 1918, 40, 1361.

24. Freundlich, H.; Z. Phys. Chem. 1906, 40, 1361.

25. Liu, Y.; Xu, H.; Yang, S.-F.; Tay, J.-H.; J. Biotechnol. 2003, 102, 233. 
26. Sips, R.; J. Chem. Phys. 1948, 16, 490.

27. Lima, É. C.; Adebayo, M. A.; Machado, F. M. In Carbon Nanomaterials as Adsorbents for Environmental and Biological Applications; Bergmann, C. P.; Machado, F. M., eds.; Springer International Publishing: Cham, 2015.

28. Music, S.; Filipovic-Vincekovic, N.; Sekovanic, L.; Braz. J. Chem. Eng. 2011, 28, 89.

29. Hu, S.; Hsieh, Y.-L.; ACS Sustainable Chem. Eng. 2014, $2,726$.

30. Baer, D. R.; Engelhard, M. H.; Johnson, G. E.; Laskin, J.; Lai, J.; Mueller, K.; Munusamy, P.; Thevuthasan, S.; Wang, H.; Washton, N.; Elder, A.; Baisch, B. L.; Karakoti, A.; Kuchibhatla, S. V. N. T.; Moon, D.; J. Vac. Sci. Technol., A 2013, 31, 50820.

31. Mourhly, A.; Khachani, M.; El Hamidi, A.; Kacimi, M.; Halim, M.; Arsalane, S.; Nanomater. Nanotechnol. 2015, 5, 35.

32. Vono, L. L. R.; Damasceno, C. C.; Matos, J. R.; Jardim, R. F.; Landers, R.; Masunaga, S. H.; Rossi, L. M.; Pure Appl. Chem. 2018, 90, 133.

33. Rouquerol, J.; Rouquerol, F.; Sing, K. In Absorption by Powders and Porous Solids, $1^{\text {st }}$ ed.; Elsevier: San Diego, 1998.

34. dos Santos, R. M. M.; Gonçalves, R. G. L.; Constantino, V. R. L.; Santilli, C. V.; Borges, P. D.; Tronto, J.; Pinto, F. G.; Appl. Clay Sci. 2017, 140, 132.

35. Sing, K. S. W.; Pure Appl. Chem. 1985, 57, 603.

36. Bhakta, S.; Dixit, C. K.; Bist, I.; Jalil, K. A.; Suib, S. L.; Rusling, J. F.; Mater. Res. Express 2016, 3, 075025.

37. Huang, C.-H.; Chang, K.-P.; Ou, H.-D.; Chiang, Y.-C.; Wang, C.-F.; Microporous Mesoporous Mater. 2011, 141, 102.
38. Mouni, L.; Belkhiri, L.; Bollinger, J.-C.; Bouzaza, A.; Assadi, A.; Tirri, A.; Dahmoune, F.; Madani, K.; Remini, H.; Appl. Clay Sci. 2018, 153, 38.

39. Jantawatchai, K.; Jitpluem, S.; Kerdlap, W.; Phanawadee, P.; Warakulwit, C.; Chisti, Y.; Hansupalak, N.; Chem. Eng. Commun. 2017, 204, 1452.

40. Jamwal, H. S.; Kumari, S.; Chauhan, G. S.; Reddy, N. S.; Ahn, J.-H.; J. Environ. Chem. Eng. 2017, 5, 103.

41. De Gisi, S.; Lofrano, G.; Grassi, M.; Notarnicola, M.; Sustainable Mater. Technol. 2016, 9, 10.

42. Sulistiyo, Y. A.; Andriana, N.; Piluharto, B.; Zulfikar, Z.; Bull. Chem. React. Eng. Catal. 2017, 12, 263.

43. Russo, V.; Masiello, D.; Trifuoggi, M.; Di Serio, M.; Tesser, R.; Chem. Eng. J. 2016, 302, 287.

44. Hu, J.; Liu, L.; Xiao, Z.; RSC Adv. 2015, 5, 68092.

45. Ghorai, S.; Sarkar, A.; Raoufi, M.; Panda, A. B.; Schönherr, H.; Pal, S.; ACS Appl. Mater. Interfaces 2014, 6, 4766.

46. Kushwaha, A. K.; Gupta, N.; Chattopadhyaya, M. C.; Desalin. Water Treat. 2014, 52, 4527.

47. Huang, C. Q.; Zhang, X.; Qiu, D. C.; Wei, H. J.; Adv. Mater. Res. 2012, 557-559, 427.

Submitted: October 23, 2018

Published online: March 27, 2019 